\title{
Flank bulge following supracostal percutaneous nephrolithotomy: A report of 2 cases
}

\author{
Andrea G. Lantz, MD, FRCSC,; Kenneth T. Pace, MD, MSc, FRCSC; $R$. John D'A. Honey, MA, MB, BChir, \\ FRCS(E) FRCSC
}

*Department of Urology, Dalhousie University, Halifax, NS; "St. Michael's Hospital, University of Toronto, Division of Urology, Department of Surgery, Toronto, ON

Cite as: Can Urol Assoc J 2013;7(7-8):e547-9. http://dx.doi.org/10.5489/cuaj.176

Published online August 19, 2013.

\section{Abstract}

Damage to intercostal nerves during surgical procedures has been associated with a postoperative flank bulge, due to denervation of the anterolateral abdominal wall musculature. This complication has not been reported following percutaneous nephrolithotomy (PCNL). We are aware of 3 cases, but have details on 2 cases of postoperative flank bulge following supracostal PCNL which are reported here. We also suggest how this complication could potentially be minimized.

\section{Introduction}

Percutaneous nephrolithotomy (PCNL) has an established role in the treatment of patients with complex urolithiasis and has evolved since its introduction in the 1970s. ${ }^{1}$ PCNL is generally a safe, minimally invasive treatment option, in appropriately selected patients, with a relatively low rate of serious complications. ${ }^{2}$ Complications range from clinically insignificant bleeding and postoperative fever, to more serious complications, such as bleeding requiring blood transfusion, fluid extravasation, urinary fistula, sepsis, organ injuries including pleural injuries (pneumothorax, hydrothorax, and hemothorax), injury to abdominal viscera (colon, duodenum, liver, and spleen) and rarely death. ${ }^{2}$

Supracostal access into the upper posterior calyceal system is an ideal access choice in some circumstances, such as the obese patient, patients with staghorn calculi and those with stones in the renal pelvis and multiple lower pole calyces. Upper pole access provides direct access to the upper calyceal system, renal pelvis, the lower calyceal system and the proximal ureter. Working down the axis of the kidney,
PCNL minimizes the torque put on the nephrostomy tract, while accessing these locations with a rigid nephroscope. ${ }^{3}$ Supracostal upper pole access has been associated with higher pulmonary complications compared to subcostal upper pole or lower pole access; however, this has not been found in all series and the rates of complications vary widely between reports. ${ }^{3-8}$ Supracostal access for percutaneous nephrolithotomy has been associated with increased pain compared to subcostal access. ${ }^{8,9}$ Damage to, or irritation of, the intercostal nerves has been suggested as a cause of this increased pain. ${ }^{10}$ Our cases report a previously unreported complication of supracostal access for PCNL, flank bulge, which may be related to damage to the intercostal nerve. ${ }^{10}$

\section{Case 1}

A 43-year-old woman was treated for staghorn calculus that extended into the upper, mid and lower pole infundibulae measuring $4.3 \mathrm{~cm} \times 3.7 \mathrm{~cm}$. The PCNL was performed in the prone-flexed position used by our group, which has been previously described. ${ }^{11}$ A supra- $12^{\text {th }}$ rib access was used to enter a posterior upper pole calyx. A ureteral stent was placed at the end of the procedure with no nephrostomy tube drainage postoperatively, as is the routine procedure in uncomplicated cases at our institution. Fluoroscopy was used at the end of the case to examine the thorax and there was no evidence of pulmonary complication. The procedure was successful and the patient was discharged on postoperative day one after removal of her Foley catheter. One week later, the patient was seen at follow-up and complained of an unsightly painless bulge of the left flank (Fig. 1, Fig. 2 ). She was otherwise well and stone-free. An ultrasound was performed and ruled out a subcutaneous collection. At further follow-up, the bulge had resolved. It lasted about 6 weeks in total. 


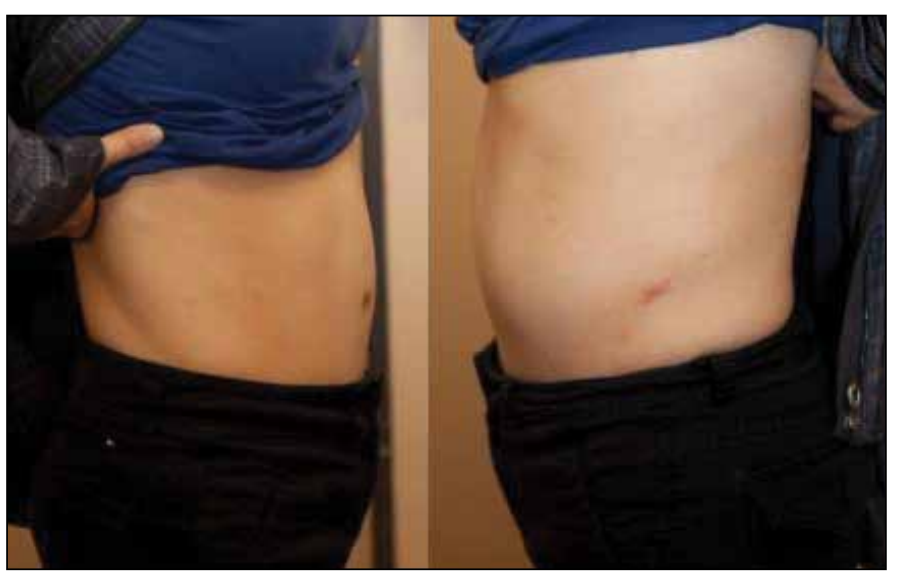

Fig. 1. Case 1: Lateral views.

\section{Case 2}

A 54-year old woman was referred for bilateral staghorn calculi. She underwent an uneventful, successful right PCNL prior to treatment of the right staghorn calculus. Treatment of the left staghorn calculus involved a posterior upper pole approach through the $12^{\text {th }}$-intercostal space in the proneflexed position. There were no intraoperative complications, a ureteral stent was placed without nephrostomy drainage, and there was no evidence of hydro- or pneumothorax on postoperative fluoroscopy of the chest. She was discharged a day after surgery. The patient was seen 1 week postoperatively for follow-up and stent removal. She complained of painless left flank bulging, which was seen on physical examination. By her next follow-up visit, tone had returned to her lateral abdominal musculature with resolution of the flank bulge, which had lasted about 4 weeks in total.

\section{Discussion}

Flank bulge has never been reported following PCNL; however, flank bulge is a known potential complication of flank incisions for various retroperitoneal surgical procedures and has been reported in the urological, ${ }^{12}$ vascular $^{13}$ and neurosurgical literature. ${ }^{14,15}$ Flank bulge due to laxity of the anterolateral abdominal musculature may be caused by damage to intercostal nerves. ${ }^{14}$ In a cadaveric and electrophysiological study, Fahim and colleagues showed that the most significant intercostal nerve contributions to the anterolateral wall came from the T11 and T12 nerves. ${ }^{14}$ They concluded that postoperative flank bulge was likely due to denervation of the abdominal musculature from injury to the T11 and T12 intercostal nerves.

McAllister and colleagues characterized key anatomical relationships relevant to PCNL through anatomical dissection of the $11^{\text {th }}$ intercostal space. ${ }^{10}$ They recorded the distance of the intercostal neurovascular structures from the $11^{\text {th }}$ rib at 3

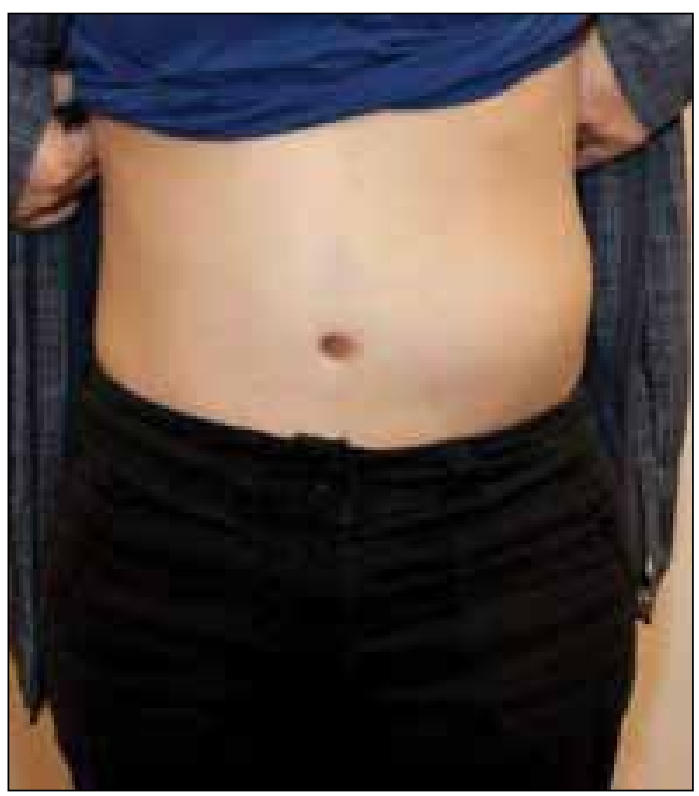

Fig. 2. Case 1: Anterior view.

sites: lateral border of the paraspinous muscle, the midscapular line and the posterior axillary line. It was shown that the intercostal nerve was exposed to injury in $85 \%$ of the cadavers at the lateral border of the paraspinous muscle, and in $100 \%$ at both the mid-scapular line and the posterior axillary line. Exposure of the intercostal artery and vein also increased as one moved lateral in the dissections; however, there was a significantly greater risk of intercostal nerve injury compared to the artery or vein at all 3 sites. This McAllister study suggests that supracostal PCNL should be performed with access just lateral to the paraspinous muscle in the lower half of the $11^{\text {th }}$ intercostal space to decrease the risk of damage to the intercostals neurovascular structures. ${ }^{10}$ However, some authors advocate more lateral placement of access tracts lateral to the midscapular line to minimize the risk of pulmonary complications during supracostal PCNL. ${ }^{8}$

We aim to access the posterior upper pole calyx at about 30 degrees from the vertical. This tends to be close to the mid-scapular line. Unfortunately, this is where the nerve is exposed and is more vulnerable to damage. We also prefer to insert the needle on the superior aspect of the $12^{\text {th }}$ rib. However, often, to access an upper calyx during expiration, it is necessary to move more superiorly, making intercostal nerve injury more likely.

\section{Conclusion}

This is the first report of flank bulge as a complication of PCNL and it is presumed to be due to damage to the $11^{\text {th }}$ intercostal nerve during supracostal access to the upper pole. It is unknown what the true incidence of this complication is, and, as our report shows, it appears to be transient in some 
cases. This complication may potentially be minimized by avoiding too lateral an access site and keeping the needle puncture closer to the $12^{\text {th }}$ rib than the $11^{\text {th }}$ rib.

Competing interests: None declared.

This paper has been peer-reviewed.

\section{References}

1. Fernstrom I, Johansson B. Percutaneous pyelolithotomy. A new extraction technique. Scand I Urol Nephrol 1976;10:257-9.

2. Michel MS, Trojan L, Rassweiler JJ. Complications in percutaneous nephrolithotomy. Eur Urol 2007; 51:899-906. http://dx.doi.org/10.1016/i.eururo.2006.10.020

3. Munver R, Delvecchio FC, Newman GE, et al. Critical analysis of supracostal access for percutaneous rena surgery. J Urol 2001;166:1242-6. http://dx.doi.org/10.1016/S0022-5347(05)65745-X

4. Lang $E$, Thomas $R$, Davis $R$, et al. Risks, advantages, and complications of intercostal vs subcostal approach for percutaneous nephrolithotripsy. Urology 2009;74:751-5. http://dx.doi.org/10.1016/i. urology.2009.04.087

5. Honey RJ, Wiesenthal JD, Ghiculete D, et al. Comparison of supracostal versus infracostal percutaneous nephrolithotomy using the novel prone-flexed patient position. J Endourol 2011;25:947-54. http:// dx.doi.org/10.1089/end.2010.0705

6. Golijanin D, Katz R, Verstandig A, et al. The supracostal percutaneous nephrostomy for treatment of staghorn and complex kidney stones. J Endourol 1998;12:403-5. http://dx.doi.org/10.1089/ end. 1998.12 .403
7. Stening SG, Bourne S. Supracostal percutaneous nephrolithotomy for upper pole caliceal calculi. J Endourol 1998;12:359-62. http://dx.doi.org/10.1089/end.1998.12.359

8. Shah HN, Hegde SS, Shah JN, et al. Safety and efficacy of supracostal access in tubeless percutaneous nephrolithotomy. J Endourol 2006;20:1016-21. http://dx.doi.org/10.1089/end.2006.20.1016

9. Andreoni C, Olweny E0, Portis AJ, et al. Effect of single-dose subarachnoid spinal anesthesia on pain and recovery after unilateral percutaneous nephrolithotomy. J Endourol 2002;16:721-5. http://dx.doi. org/10.1089/08927790260472863

10. Mcallister $M$, Lim K, Torrey $R$, et al. Intercostal vessels and nerves are at risk for injury during supracostal percutaneous nephrostolithotomy. J Urol 2011;185:329-34. http://dx.doi.org/10.1016/i. juro.2010.09.007

11. Ray AA, Chung DG, Honey RJ. Percutaneous Nephrolithotomy in the Prone and Prone-Flexed Positions: Anatomic Considerations. J Endourol 2009;23:1607-14. http://dx.doi.org/10.1089/end.2009.0294

12. Chatterjee $S$, Nam R, Fleshner $N$, et al. Permanent flank bulge is a consequence of flank incision for radical nephrectomy in one half of patients. Urol Oncol 2004;22:36. http://dx.doi.org/10.1016/ S1078-1439(03)00099-1

13. Gardner $G P$, Josephs $L G$, Rosca $M$, et al. The retroperitoneal incision. An evaluation of postoperative flank 'bulge'. Arch Surg 1994;129:753-6. http://dx.doi.org/10.1001/archsurg.1994.01420310085015

14. Fahim DK, Kim SD, Cho D et al: Avoiding abdominal flank bulge after anterolateral approaches to the thoracolumbar spine: cadaveric study and electrophysiological investigation. J Neurosurg Spine 2011;15:53240. http://dx.doi.org/10.3171/2011.7.SPINE10887

15. Jagannathan J, Chankaew E, Urban P, et al: Cosmetic and functional outcomes following paramedian and anterolateral retroperitoneal access in anterior lumbar spine surgery. J Neurosurg Spine 2008;9:454-65. http://dx.doi.org/10.3171/SPI.2008.9.11.454

Correspondence: Dr. R. John D'A. Honey, Professor, Department of Surgery, University of Toronto, St. Michael's Health Centre, 61 Queen St. East, Suite 9-103, Toronto, ON M5C 2T2; fax: 416867-7433; honeyi@smh.ca 